\title{
Design and MultiPlierless Realization of ECG- Based Gaussian Wavelet Filter with Lattice Structures
}

\author{
Dr. Jassim M. Abdul-Jabbar \\ Computer Engineering Department, \\ College of Eng., University of Mosul, \\ Mosul, Iraq.drissm@yahoo.com
}

\author{
Abdulhamed M. Jasim \\ Department of Electronic, College of \\ Electronics Eng., University of Mosul, \\ Mosul, Iraq.hammoh85@yahoo.com
}

\begin{abstract}
In this paper, the Gaussian function is selected as a mother wavelet function and utilized in the design of some corresponding filter banks. With a $1^{\text {st }}$ derivation of the Gaussian function, a similar shape to QRS complex part of the ECG is achieved.It can be used for QRS feature extraction.Using thesymmetry property of the mother wavelet function, the designed FIR wavelet filter banks can be realized in highly-efficient lattice structures which are easy to implement. The resulting lattice structures reduces the number of filter banks coefficients and this reduces, in turn the number of multiplications and improves the filter banks efficiencies as it reduces the number of computations performed. Hardwarely, this leads to less-complex implementations. The resulting quantized multiplier values also lead to a multiplierless realization for such wavelet filter banks.
\end{abstract}

Keywords: ECG,Wavelet and scaling functions, Filter banks, Lattice structures, Multiplierless realization.

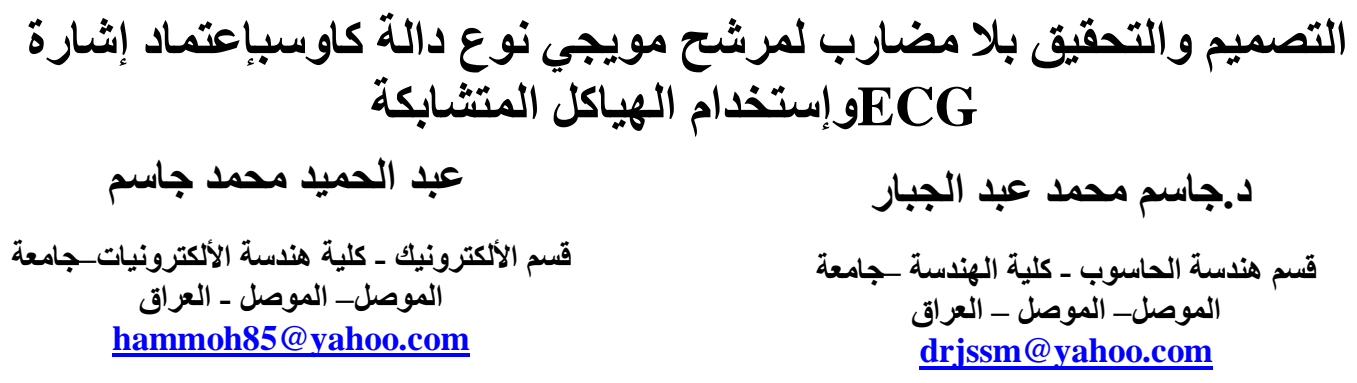

الخلاصة

في هذا البحث، تم إختيار دالة كاوس كدالة أم مويجيةّو إستغلالها لتصميم بعض أجراف مرشحات مقابلة. وبمجرد أن

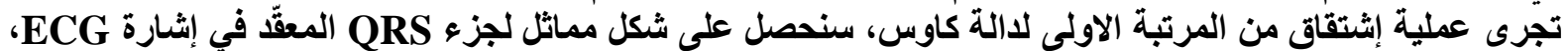

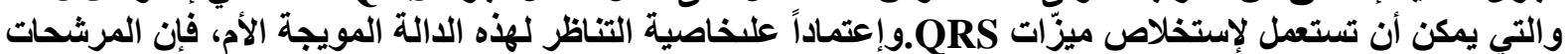

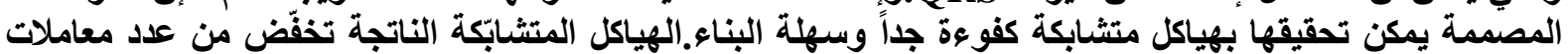

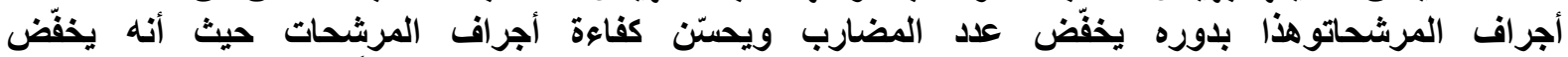

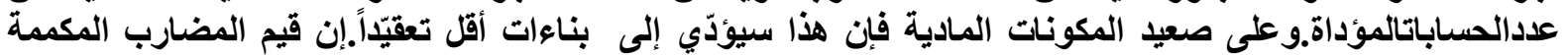

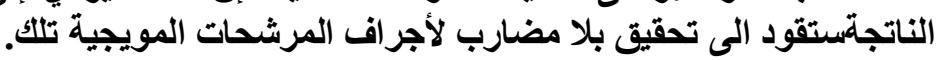

Received: 21 - 9 - 2011

Accepted: 17 - 5 - 2012 


\section{Introduction}

The electrocardiogram (ECG) is a time-varying signal that measures the electrical activity of the heart. The cardiac cycle begins with the $\mathrm{P}$ wave, which corresponds to the period of atrial depolarization in the heart. This is followed by the QRS complex, which is usually the most relevant (recognizable) feature of an ECG waveform. The T wave follows the QRS complex and corresponds to the period of ventricular repolarization(see Fig. 1)[1].

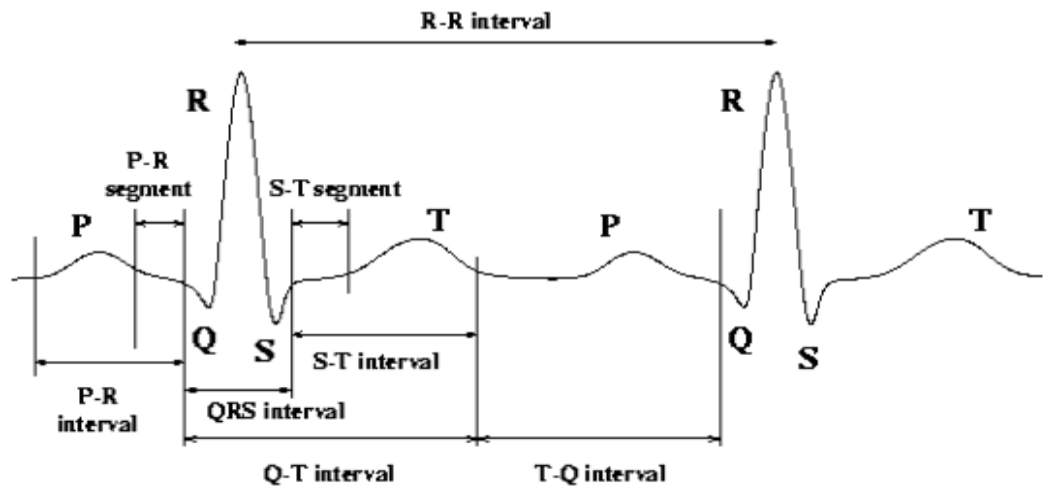

Fig.1 A Sample ECG Signal showing P-QRS-T Wave

The ECG signal represents the potential differencebetween two points on the body surface, versus time. Extracting the features from this signal has been found very helpful in explaining and identifying various cardiac arrhythmias[2].One of the most important ECG components is the QRS complex, which is associated with electrical ventricular activation[3],[4].

The ECG feature extraction system provides fundamental features (amplitudes and intervals) to be used in subsequent automatic analysis. In recent times, many techniques have been proposed to detect these features [5],[6]. Most of the previously proposed techniques for ECG signal analysis were based on time domain analysis. But this is not always adequate to study all the features of ECG signals. Therefore, the frequency representation of a signal is required. In recent years, many classifying methods which have been proposed including digital signal analysis, Fuzzy Logic methods, Artificial Neural Networks, Hidden Markov Model, Genetic Algorithm, Support vector Machines, Self-Organizing Map, Bayesian and other hybrid methods. Each of these approaches exhibits its own advantages and disadvantages [6].

The wavelet transform (WT) is one of several mathematical tools that is useful in the analysis and design of systems and signals. Its representation basically involves the decomposition of the signals in terms of small wave components called wavelets. Wavelet theory is employed in many fields and applications such as signal and image processing, communication systems, many other signal analysis and system control areas[7].The wavelet transform is an efficient technique for a non-stationary signal processing. ECG signal is one of the biosignals that is considered as a non-stationary one[8].There are many sets of wavelet bases that can be used to represent a signal. Each basis in a certain wavelet set is constructed form one function called the mother wavelet $\varphi(t)$. The multiresolutionanalysis of signals using wavelets involves two basic operations on the mother wavelet. These operations are the scale operation, and translation operation[7]. 
The Gaussian function is perfectly local in both time and frequency domains and is indefinitely derivable. Any $n^{\text {th }}$ order derivative of Gaussian function may be considered as a Wavelet Transform (WT). For cardiac signal characterization, a $1^{\text {st }}$ order derivative Gaussian wavelet function is of interest [9]. The proposed design is obtained by simulating the $1^{\text {st }}$ order derivative Gaussian system using a Gaussian system convolution stage with input signal $x(\mathrm{n})$ and differentiating the result. Due to linearity of system stages, the proposed digital-version system can be reordered as shown in Fig. 2 with $\nabla$ as the $1^{\text {st }}$ order backward difference operator.

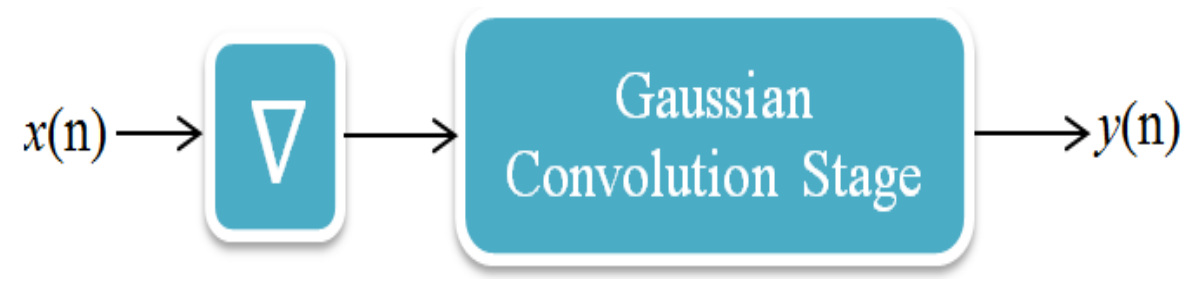

Fig.2A proposed system with Gaussian function and a derivative stage.

The resulting wavelet filter banks can be realized in highly-efficient lattice structures which are easy to implement. The lattice structure reduces the number of coefficients and this, in turn reduces the number of multiplications and improves both; filter bank complexity and processing speed, as it reduces the number of computations performed [10]. Hardwarely, lattice structure leads to less-complex implementations.

Besides this introductory section, Section II of this paper contains the design of the FIR wavelet filter utilizing the Gaussian function as a mother wavelet function. Section III illustrates the lattice structure of such filter with a standard deviation $\sigma=1$. A multiplierless realization of such structure is also proposed in this section. The lattice structure of the proposed filter with a standard deviation $\sigma=2$ and its multiplierless realization are then described in section IV.The extracted features from some ECG signals representing a group of diseases in addition to the normal state are given in section V. Finally, Section VI concludes this paper.

\section{Wavelet Filter Design}

One of the functions in the wavelet techniques is the Gaussian function (see Fig. 3) that is defined by

$\varphi(t)=\frac{1}{\sigma \sqrt{2 \pi}} e^{-\left(\frac{(t-m)^{2}}{2 \sigma^{2}}\right)}$

where $\varphi(t)$ is the Gaussian function in term the time $t . \sigma$ is the standard deviation and $m$ is the center of the wave.

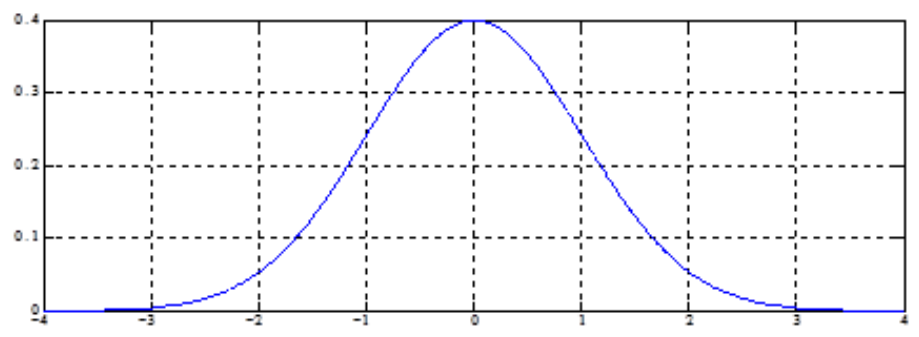

Fig. 3 The Gaussian function. 
In this paper, the Gaussian function is selected as a mother wavelet function. The $1^{\text {st }}$ order derivative Gaussian function shown in Fig. 4, has a similar shape to QRS complex part of the ECG and can be used for QRS feature extraction. It is given by

$\varphi^{\prime}(t)=\frac{m-t}{\sigma^{3} \sqrt{2 \pi}} e^{-\left(\frac{(t-m)^{2}}{2 \sigma^{2}}\right)}$

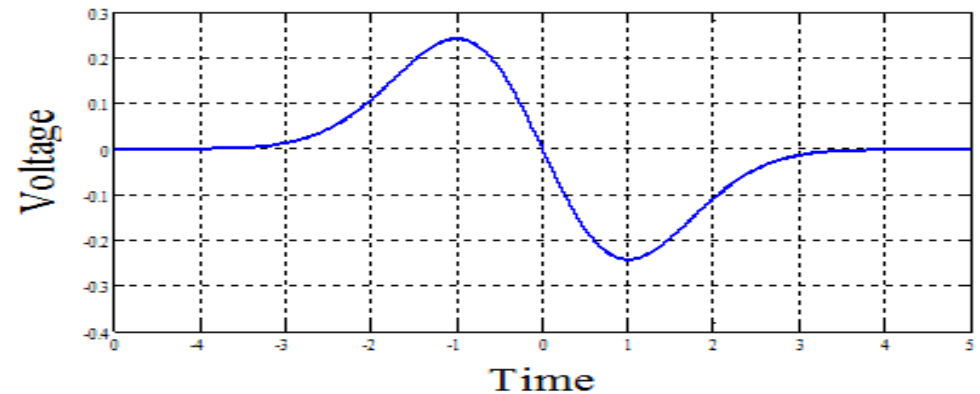

Fig. 4 The $1^{\text {st }}$ derivative Gaussian function.

In order to design a corresponding FIR wavelet filter, the values of such FIR filter coefficients simulating the Gaussian response must be determined. To do so, the Gaussian function must be truncated in a way that assumes getting coefficients number depends upon standard deviation within the truncated function. To determine the values of these coefficients, the value of the standard deviation $\sigma$ must be determined. The Gaussian function is approximately zero for $|t|>4 \sigma$. For example, $\varphi^{\prime}(t, \sigma)<0.0004$ for $|t|>4 \sigma$. [11].

As shown in Fig. 3, since the response of designed FIR Gaussian wavelet filter stage of Fig. 2 possesses thesymmetry property, then the required number of filter coefficients $(i$. e., multipliers) is $(1+4 \sigma)$. Therefore, such FIR wavelet filter can be designed at various values of standard deviation, $\sigma$. Next section shows the design of FIR wavelet filters at $\sigma=1$ and $\sigma=2$.

\section{Gaussian FIR Wavelet Filter with $\sigma=1$}

\section{a) Lattice Structure}

In the caseof $\sigma=1$, the resulting filter response shown in Fig. 5, corresponds to the sampled version of the mother wavelet function in Fig. 3. It will have 9 coefficients with the following system function:

$H(z)=h_{0}+h_{1} z^{-1}+h_{2} z^{-2}+h_{3} z^{-3}+h_{4} z^{-4}+h_{5} z^{-5}+h_{6} z^{-6}+h_{7} z^{-7}+h_{8} z^{-8}$

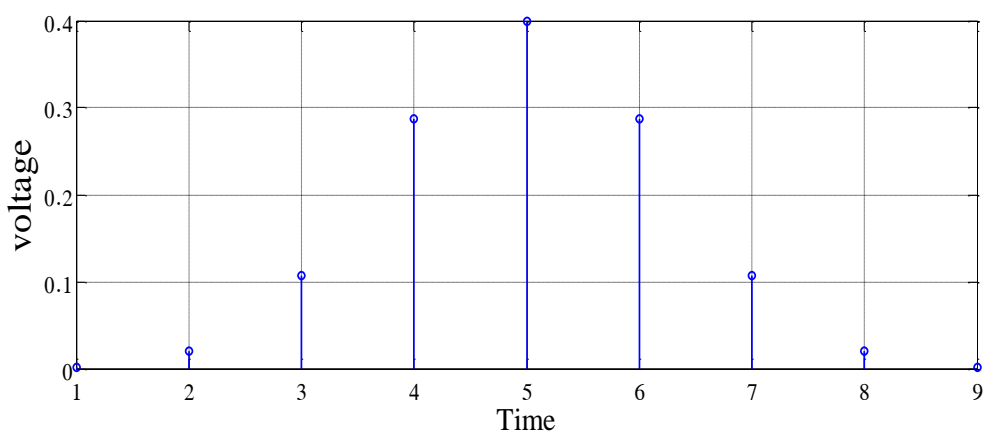

Fig. 5 Impulse response of the Gaussian filter stage. 
By the property of quadrature mirror filters (QMFs), $G(\mathrm{z})=H(-\mathrm{z})$, the system function $G(\mathrm{z})$ that corresponds to the scaling function can be written as

$G(z)=h_{0}-h_{1} z^{-1}+h_{2} z^{-2}-h_{3} z^{-3}+h_{4} z^{-4}-h_{5} z^{-5}+h_{6} z^{-6}-h_{7} z^{-7}+h_{8} z^{-8}$

The first design step is to find the polyphase matrix of the specified filter bank and a similar matrix of the proposed lattice structure. The block diagram of lattice structure of the proposed FIR wavelet filter is shown in Fig. 6 , where $\nabla^{2}$ represents the down sampled version of the $1^{\text {st }}$ order backward difference operator.The filters' polyphase representations are expressed asfunctions of $z$, by

$\left.\begin{array}{l}H_{\text {even }}\left(z^{2}\right)=h_{0}+h_{2} z^{-2}+h_{4} z^{-4}+h_{6} z^{-6}+h_{8} z^{-8} \\ H_{\text {odd }}\left(z^{2}\right)=h_{1}+h_{3} z^{-2}+h_{5} z^{-4}+h_{7} z^{-6}\end{array}\right\}$

The down-sampled (by 2) form of equation (5) can be written as

$H_{\text {even }}(z)=h_{0}+h_{2} z^{-1}+h_{4} z^{-2}+h_{6} z^{-3}+h_{8} z^{-4}$

$H_{o d d}(z)=h_{1}+h_{3} z^{-1}+h_{5} z^{-2}+h_{7} z^{-3}$

Therefore,

$\left.\begin{array}{l}H(z)=H_{\text {even }}(z)+z^{-1} H_{\text {odd }}(z) \\ \text { And } \\ G(z)=H_{\text {even }}(z)-z^{-1} H_{\text {odd }}(z)\end{array}\right\}$

with the following coefficients values:

$h_{0}=h_{8}=0.0021, h_{1}=h_{7}=0.0208, h_{2}=h_{6}=0.1074, h_{3}=h_{5}=0.2874$

and $h_{4}=0.3989$.

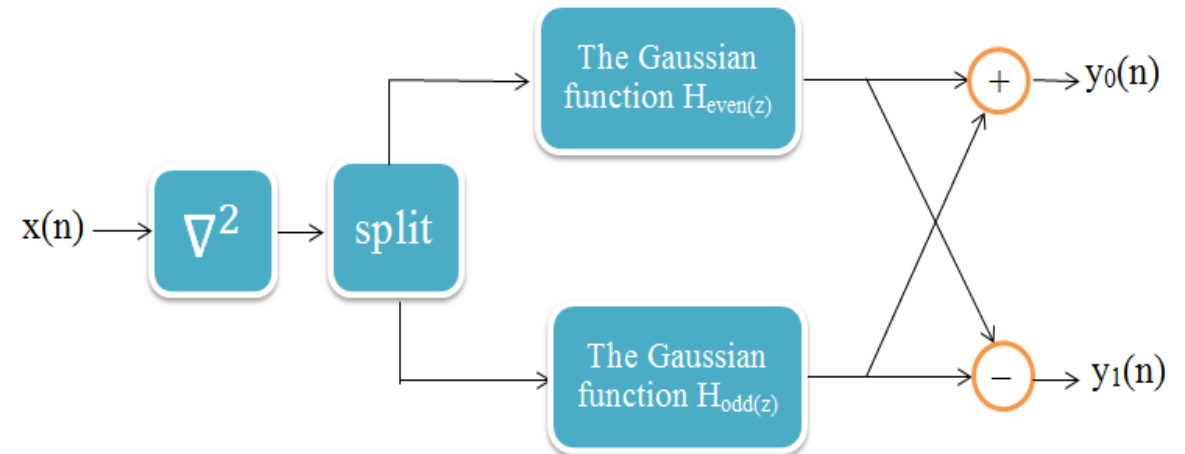

Fig. 6 Block diagram of lattice structure of the proposed FIR wavelet filter.

The values of coefficients can be scaled (by $\alpha$ ) to give a maximum frequency response value equals to one, for the case of no-energy level variation during transformation. This value of $\alpha$ for $\left[\left|H\left(e^{j \omega}\right)\right| \leq 1\right]$ turns to be 0.81 . Therefore, the new scaled coefficients values are as follows:

$h_{0}=h_{8}=0.0017, h_{1}=h_{7}=0.0169, h_{2}=h_{6}=0.0870, h_{3}=h_{5}=0.2328$ and $h_{4}=0.3231$. 
After getting these coefficients, the design of the proposed FIR wavelet filter is accomplished. The magnitude and phase responses of $H\left(e^{j \omega}\right)$ of the system function in equation (7), are shown in Fig. 7. The final overall lattice structure in Matlab simulation is shown in Fig. 8.

Magnitude (dB) and phase responses

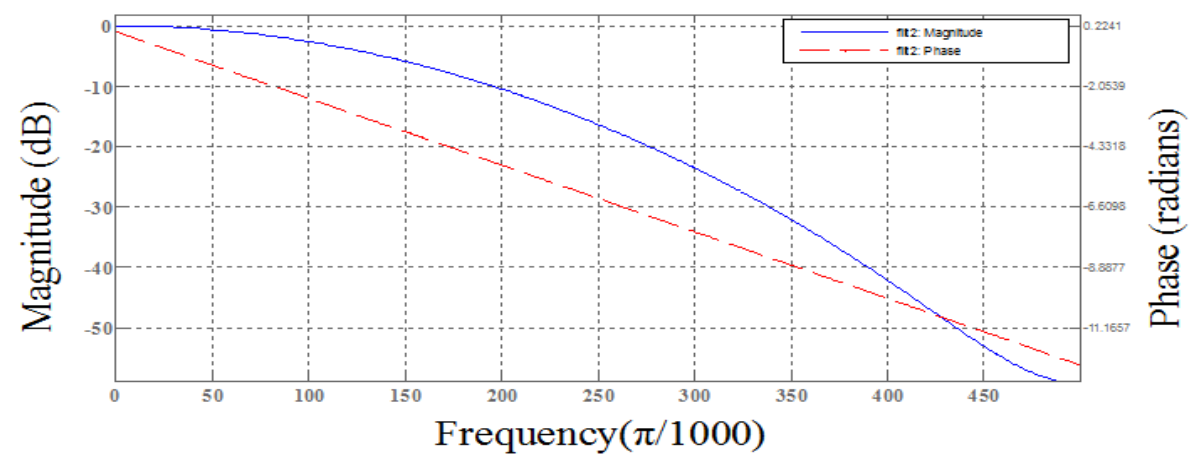

Fig. 7 The magnitude and phase responses of $H\left(e^{j \omega}\right)$ with $(\sigma=1)$.

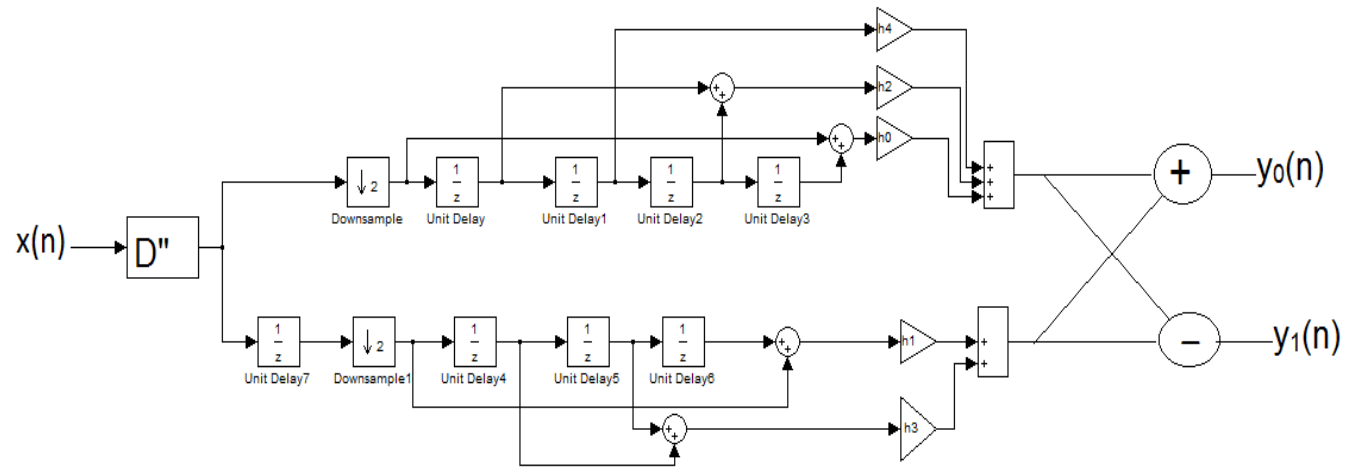

Fig. 8 The final lattice FIR wavelet filter bank structure with $(\sigma=1)$.

\section{b) A Multiplierless Realization}

The rounded values of the resulting scaled coefficients for different wordlengths are illustrated in Table 1.

Table 1 The rounded coefficient values for different wordlengths.

\begin{tabular}{|c|c|c|c|c|c|c|c|c|}
\hline $\begin{array}{c}\text { Wordlength } \\
\text { (bits) }\end{array}$ & \multicolumn{7}{|c|}{ Coefficients for different wordlengths } \\
\cline { 2 - 8 } $\begin{array}{l}\text { Original } \\
\text { Coefficient }\end{array}$ & 3 & 4 & 5 & 6 & 7 & 8 & 9 & 10 \\
\hline $\mathbf{0 . 0 0 1 7}$ & 0 & 0 & 0 & 0 & 0 & 0 & 0 & $9.7656 e-4$ \\
\hline $\mathbf{0 . 0 1 6 9}$ & 0 & 0 & 0 & 0.0156 & $\mathbf{0 . 0 1 5 6}$ & $\mathbf{0 . 0 1 5 6}$ & $\mathbf{0 . 0 1 5 6}$ & $\mathbf{0 . 0 1 6 6}$ \\
\hline $\mathbf{0 . 0 8 7 0}$ & $\mathbf{0}$ & $\mathbf{0 . 0 6 2 5}$ & $\mathbf{0 . 0 6 2 5}$ & $\mathbf{0 . 0 7 8 1}$ & $\mathbf{0 . 0 8 5 9}$ & $\mathbf{0 . 0 8 5 9}$ & $\mathbf{0 . 0 8 5 9}$ & $\mathbf{0 . 0 8 6 9}$ \\
\hline $\mathbf{0 . 2 3 2 8}$ & $\mathbf{0 . 1 2 5 0}$ & $\mathbf{0 . 1 8 7 5}$ & $\mathbf{0 . 2 1 8 8}$ & $\mathbf{0 . 2 1 8 8}$ & $\mathbf{0 . 2 2 6 6}$ & $\mathbf{0 . 2 3 0 5}$ & $\mathbf{0 . 2 3 2 4}$ & $\mathbf{0 . 2 3 2 4}$ \\
\hline $\mathbf{0 . 3 2 3 1}$ & $\mathbf{0 . 2 5 0 0}$ & $\mathbf{0 . 3 1 2 5}$ & $\mathbf{0 . 3 1 2 5}$ & $\mathbf{0 . 3 1 2 5}$ & $\mathbf{0 . 3 2 0 3}$ & $\mathbf{0 . 3 2 0 3}$ & $\mathbf{0 . 3 2 2 3}$ & $\mathbf{0 . 3 2 2 3}$ \\
\hline
\end{tabular}

The approximated values of Table 1 are used in a Matlab simulation for best selection of maximum and average error values in the resulting filter magnitude response and the 
resulting SNR values.Calculations ofthe values of average error and deviation are carried out by following equations:

$\Delta_{\text {avg }}=(1 / m) * \sum_{1}^{m} \Delta\left(e^{j \omega}\right)$

$m=$ length of $\left(H_{0}\left(e^{j \omega}\right)\right)=$ no. of frequency samples

$\Delta\left(e^{j w}\right)=\left|H_{\text {original }}\left(e^{j \omega}\right)-H_{\text {wordlength }}\left(e^{j \omega}\right)\right|$

Deviation $=1-\max \left\{H_{\text {wordlength }}\left(e^{j \omega}\right)\right\}$

where:

$H_{\text {original }}\left(e^{j w}\right)$ is the original frequency response.

$H_{\text {wordlength }}\left(e^{j w}\right)$ is the frequency response at a specified wordlength.

Deviation is the amount of error in the frequency response at any wordlength.

From equation (8), Table 2 is obtained. It will lead us to the corrected choice for coefficients word lengths. It can be seen in Table 2 that, a wordlength of 6 bits can be chosen for acceptable values of average error and deviation. Also, Table 3 returns the suitable number of ECG samples for a maximum SNR valueof 37.0606dB.

Table 2 Maximum and average deviations.

\begin{tabular}{|c|c|c|c|c|c|c|c|c|}
\hline $\begin{array}{c}\text { Wordlengt } \\
\text { h (bits) }\end{array}$ & 3 & 4 & 5 & 6 & 7 & 8 & 9 & 10 \\
\hline$\Delta_{\text {avg }}$ & $\mathbf{0 . 1 4 5 0}$ & $\mathbf{0 . 0 5 9 9}$ & $\begin{array}{c}0.032 \\
9\end{array}$ & $\begin{array}{c}\mathbf{0 . 0 1 7} \\
7\end{array}$ & $\begin{array}{c}\mathbf{0 . 0 0 7} \\
9\end{array}$ & $\mathbf{0 . 0 0 3 5}$ & $\mathbf{0 . 0 0 2 7}$ & $\mathbf{0 . 0 0 1 1}$ \\
\hline H $_{\text {wordlength }}$ & $\mathbf{0 . 5}$ & $\begin{array}{c}\mathbf{0 . 8 1 2} \\
\mathbf{5}\end{array}$ & $\begin{array}{c}\mathbf{0 . 8 7 5} \\
1\end{array}$ & $\begin{array}{c}\mathbf{0 . 9 3 7} \\
\mathbf{5}\end{array}$ & $\begin{array}{c}\mathbf{0 . 9 7 6} \\
\mathbf{5}\end{array}$ & $\mathbf{0 . 9 8 4 3}$ & $\mathbf{0 . 9 9 0}$ & $\mathbf{0 . 9 9 6 1}$ \\
\hline Deviation & $\mathbf{0 . 5}$ & $\mathbf{0 . 1 8 7 5}$ & $\mathbf{0 . 1 2 4 9}$ & $\mathbf{0 . 0 6 2 5}$ & $\mathbf{0 . 0 2 3 5}$ & $\mathbf{0 . 0 1 5 7}$ & $\mathbf{0 . 0 0 9 9}$ & $\mathbf{0 . 0 0 3 9}$ \\
\hline
\end{tabular}

Table 3 SNR values with respect to no. of samples for the input ECGsignal.

\begin{tabular}{|c|c|c|c|c|c|c|c|c|}
\hline \multirow{2}{*}{$\begin{array}{l}\text { Wordlength } \\
\text { (bits) }\end{array}$} & \multicolumn{8}{|c|}{ SNR values in $(d B)$ for different wordlengths (in bits) } \\
\hline & 3 & 4 & 5 & 6 & 7 & 8 & 9 & 10 \\
\hline 20 & 18.7795 & 28.7430 & 29.8735 & 37.0606 & \begin{tabular}{|l|}
40.2516 \\
\end{tabular} & 52.7677 & 53.2702 & 61.0592 \\
\hline 40 & 18.7832 & 29.8413 & 31.8251 & 35.9911 & 45.4214 & 54.8581 & 51.5275 & 65.1076 \\
\hline 60 & 16.6328 & 26.9843 & 31.9761 & 34.8170 & 44.3359 & 51.0628 & 52.7310 & 60.4078 \\
\hline 80 & $\mathbf{1 6 . 6 3 5 2}$ & 26.6825 & 31.4614 & 34.9883 & 44.6972 & 50.7150 & 53.2873 & 61.8624 \\
\hline 100 & 15.2283 & 24.7151 & 29.9835 & 33.4573 & 42.7649 & 49.0411 & 54.5575 & 61.5493 \\
\hline 120 & 15.2015 & 24.7018 & 29.3972 & 33.5001 & 43.0360 & 48.3479 & 54.7324 & 61.1366 \\
\hline 140 & $\mathbf{1 5 . 2 2 9 6}$ & 24.4127 & 29.2695 & \begin{tabular}{|l|}
33.4544 \\
\end{tabular} & \begin{tabular}{|l|}
42.7619 \\
\end{tabular} & 49.9888 & 54.5697 & 61.5065 \\
\hline 160 & 15.6710 & 24.6147 & 29.2656 & 33.8426 & 42.9003 & 47.8922 & 54.0714 & 61.3886 \\
\hline 180 & 16.1534 & 25.1310 & 29.4137 & 34.3439 & 43.4716 & 48.0435 & 53.7406 & 61.2532 \\
\hline 200 & 16.6931 & 25.6434 & 29.7235 & 34.8739 & 43.9559 & 48.2593 & 53.5781 & 61.1686 \\
\hline
\end{tabular}

From Table 3, the 6-bit representation tolerates a suitable number of ECG samples of 20 samples for the pre mentioned maximum SNR value. Since the FIR filter response is 
symmetric, therefore the number of multipliers can be reduced to almost half of its original value $(1+4 \sigma)$. Thus, only5 multipliers can be used in the realization of such filter banks. From Table 1 and for 6-bit representations, the exact number of required multipliers appears to be reduced to 4 . In addition, these 4 multipliers can be represented in sum-of-power-of-two (SOPOT) resulting in a multiplier less realizations shown in Table 4.Hardwarely speaking, a limited number of shifters and adders or subtracts are needed.

Table 4, Multiplier less representation of coefficients.

\begin{tabular}{|l|l|}
\hline \multicolumn{1}{|c|}{$\begin{array}{c}\text { 6-bit representation of } \\
\text { coefficients }\end{array}$} & \multicolumn{1}{|c|}{$\begin{array}{c}\text { SOPOTrepresentation of } \\
\text { coefficients }\end{array}$} \\
\hline$h_{0}=0$ & None \\
\hline$h_{1}=0.0156$ & $2^{-6}=$ six shifts only \\
\hline$h_{2}=0.0781=0.0625+0.0156$ & $2^{-4}+2^{-6}=$ shift and add \\
\hline$h_{3}=0.2188=0.2500-0.03125$ & $2^{-2}-2^{-5}=$ shift and subtract \\
\hline$h_{4}=0.3125=0.2500+0.0625$ & $2^{-2}+2^{-4}=$ shift and add \\
\hline
\end{tabular}

\section{Gaussian FIRWavelet Filter with $\sigma=2$}

\section{a) Lattice Structure}

The same procedure of the previous section can also be followed. The filter response of $H(z)$ will have 17 coefficients with the following system function that corresponds to the samples of Fig. 9 which represent a sampled version of the original mother wavelet function with $\sigma=2$ :

$$
\begin{aligned}
H(z)= & h_{0}+h_{1} z^{-1}+h_{2} z^{-2}+h_{3} z^{-3}+h_{4} z^{-4}+h_{5} z^{-5}+h_{6} z^{-6}+h_{7} z^{-7}+h_{8} z^{-8}+ \\
& h_{9} z^{-9}+h_{10} z^{-10}+h_{11} z^{-11}+h_{12} z^{-12}+h_{13} z^{-13}+h_{14} z^{-14}+h_{15} z^{-15}+ \\
& h_{16} z^{-16}
\end{aligned}
$$

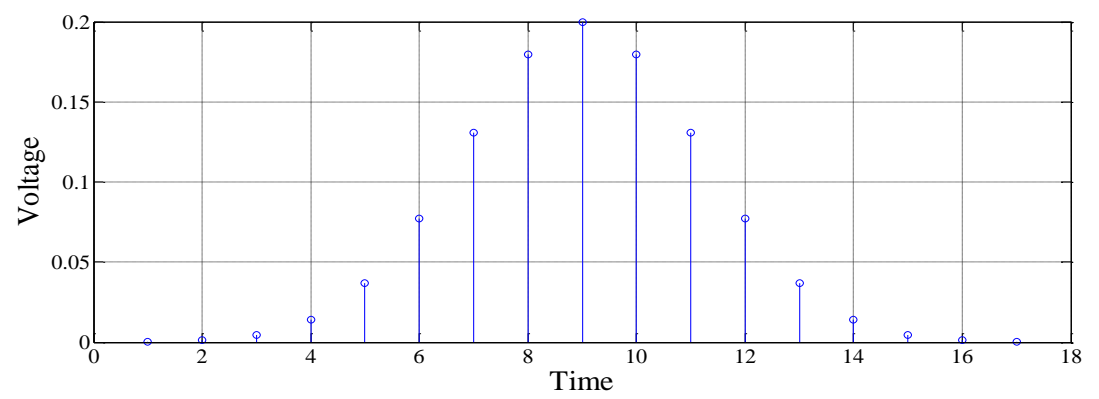

Fig. 9Impulse response of Gaussian function with $(\sigma=2)$.

By the same property of quadrature mirror filters (QMFs), $G(\mathrm{z})=H(-\mathrm{z})$, the system function $G(\mathrm{z})$ that corresponds to the scaling function can be written as

$$
\begin{aligned}
G(z)= & h_{0}-h_{1} z^{-1}+h_{2} z^{-2}-h_{3} z^{-3}+h_{4} z^{-4}-h_{5} z^{-5}+h_{6} z^{-6}-h_{7} z^{-7}+h_{8} z^{-8}- \\
& h_{9} z^{-9}+h_{10} z^{-10}-h_{11} z^{-11}+h_{12} z^{-12}-h_{13} z^{-13}+h_{14} z^{-14}-h_{15} z^{-15}+ \\
& h_{16} z^{-16}
\end{aligned}
$$

The filters' polyphase representations can then be expressed by 


$$
\left.\begin{array}{c}
H_{\text {even }}\left(z^{2}\right)=\begin{array}{rl}
h_{0} & +h_{2} z^{-2}+h_{4} z^{-4}+h_{6} z^{-6}+h_{8} z^{-8}+h_{10} z^{-10}+h_{12} z^{-12}+h_{14} z^{-14} \\
& +h_{16} z^{-16}
\end{array} \\
H_{\text {odd }}\left(z^{2}\right)=h_{1}+h_{3} z^{-2}+h_{5} z^{-4}+h_{7} z^{-6}+h_{9} z^{-8}+h_{11} z^{-10}+h_{13} z^{-12}+h_{15} z^{-14}
\end{array}\right\}
$$

The down-sampled form of equation (11) is written as

$\left.H_{\text {even }}(z)=h_{0}+h_{2} z^{-1}+h_{4} z^{-2}+h_{6} z^{-3}+h_{8} z^{-4}+h_{10} z^{-5}+h_{12} z^{-6}+h_{14} z^{-7}+h_{16} z^{-8}\right\}$ $H_{\text {odd }}(z)=h_{1}+h_{3} z^{-1}+h_{5} z^{-2}+h_{7} z^{-3}+h_{9} z^{-4}+h_{11} z^{-5}+h_{13} z^{-6}+h_{15} z^{-7}$

Therefore,

$$
\left.\begin{array}{l}
H(z)=H_{\text {even }}(z)+z^{-1} H_{\text {odd }}(z) \\
\text { and } \\
G(z)=H_{\text {even }}(z)-z^{-1} H_{\text {odd }}(z)
\end{array}\right\}
$$

with the following coefficients values:

$$
\begin{aligned}
& h_{0}=h_{16}=0.0002, h_{1}=h_{15}=0.0011, h_{2}=h_{14}=0.0044, h_{3}=h_{13}=0.0142, \\
& h_{4}=h_{12}=0.0367, h_{5}=h_{11}=0.0770, h_{6}=h_{10}=0.1306, h_{7}=h_{9}=0.1794 \\
& \text { and } h_{8}=0.1995 \text {. }
\end{aligned}
$$

Using the same previous scaling procedure, the value of $\alpha$ for $\left.\left|H\left(e^{j \omega}\right)\right| \leq 1\right]$ turns to be 0.9201 . Therefore, the new scaled coefficients values are:

$h_{0}=h_{16}=0.0002, h_{1}=h_{15}=0.0010, h_{2}=h_{14}=0.0041, h_{3}=h_{13}=0.0130$,

$h_{4}=h_{12}=0.0338, h_{5}=h_{11}=0.0708, h_{6}=h_{10}=0.1202, h_{7}=h_{9}=0.1651$ and $h_{8}=0.1835$.

In this stage of design, the number of coefficients islimited to 9 due to symmetry property. The resulting magnitude and phase responses of $H\left(e^{j \omega}\right)$ of the system function in equation (13), are shown in Fig. 10. The final lattice structure in Matlab simulation is shown in Fig. 11.

Magnitude (dB) and phase responses

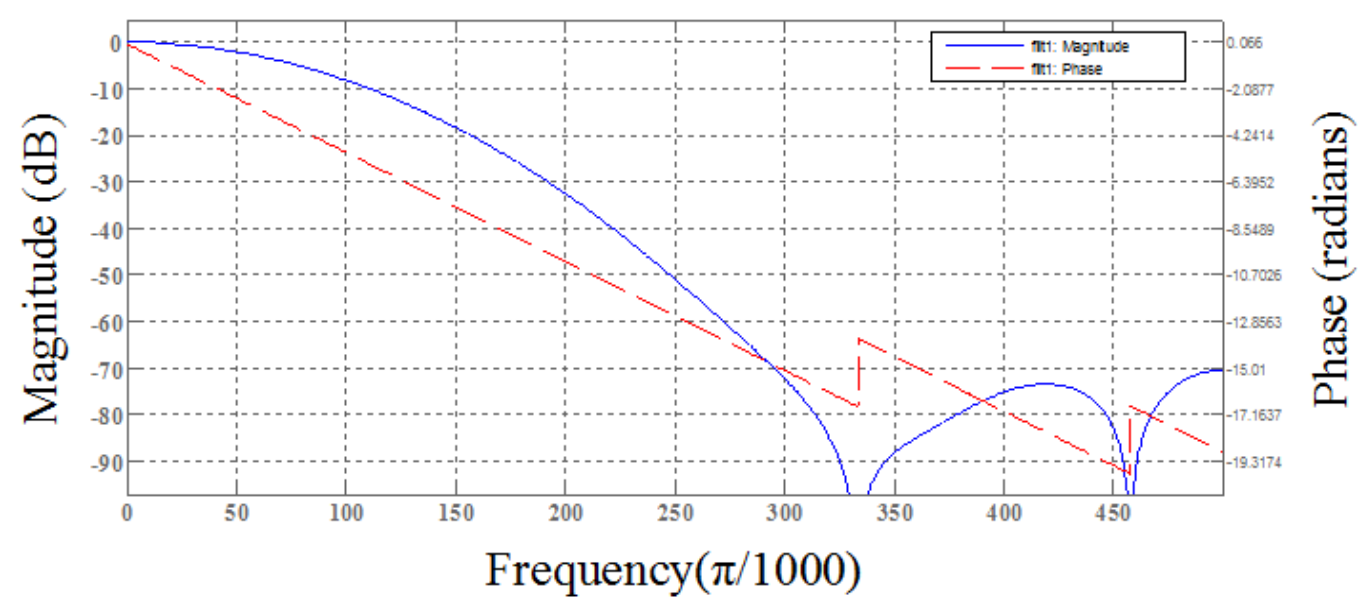

Fig. 10 The magnitude and phase responses of $H\left(e^{j \omega}\right)$ with $(\sigma=2)$. 


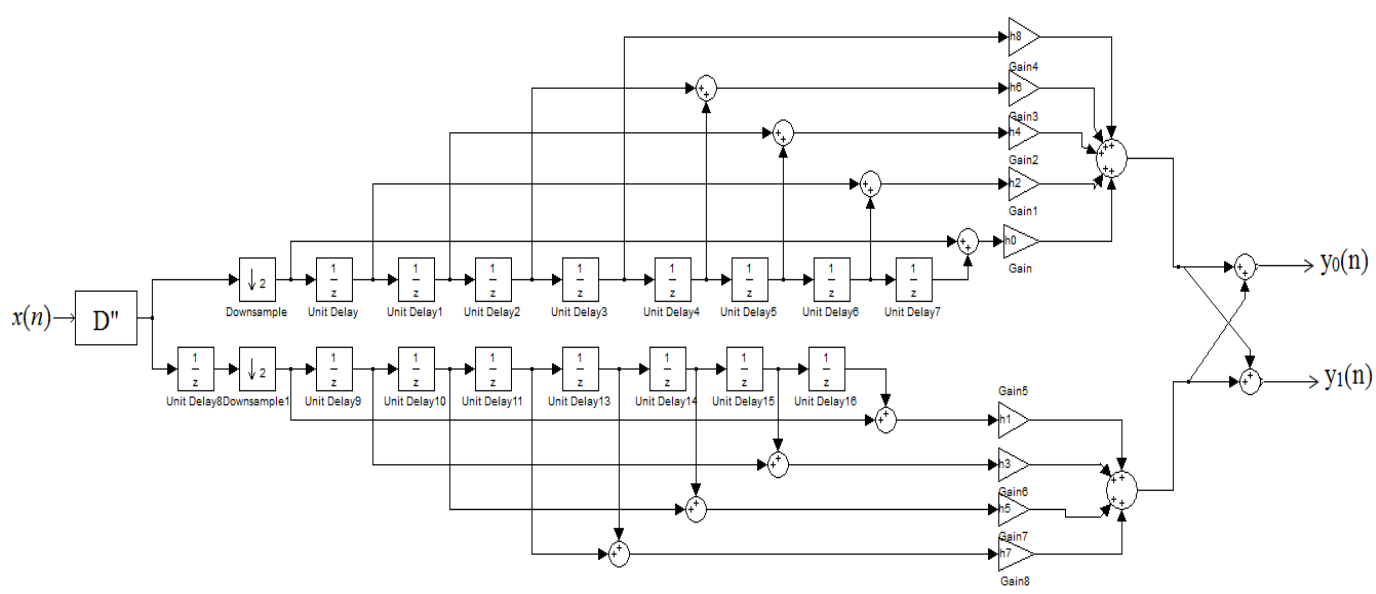

Fig. 11 The final lattice FIR wavelet filter bank structure with $(\sigma=2)$.

\section{b) A Multiplierless Realization}

By the same previous procedure, awordlength of 6 bitscan also be chosen where the maximum and average deviations are acceptable (maximum error is $0.0389 \&$ average deviation is 0.0088) and the maximum SNR value is 46.2504dBat an ECG number of samples of 20. Using 6-bit representations, the exact number of required multiplierscan further be reduced to5. In addition, such multipliers can be represented in SOPOT, resulting in a multiplierless realizationas shown in Table 5.

Table 5 Multiplierless representation of coefficients.

\begin{tabular}{|l|l|}
\hline \multicolumn{1}{|c|}{$\begin{array}{c}\text { 6-bit representation of } \\
\text { coefficients }\end{array}$} & \multicolumn{1}{c|}{$\begin{array}{c}\text { SOPOT representation of } \\
\text { Coefficients }\end{array}$} \\
\hline$h_{0}=h_{1}=h_{2}=h_{3}=0$ & None \\
\hline$h_{4}=0.0313$ & $2^{-5}=$ Five shifts (a shifter only) \\
\hline$h_{5}=0.0625$ & $2^{-4}=$ Four shifts (a shifter only) \\
\hline$h_{6}=\mathbf{0 . 1 0 9 4}=0.1250-0.0156$ & $2^{-3}-2^{-6}=$ shift and subtract \\
\hline$h_{7}=0.1563=0.1250+0.0313$ & $2^{-3}+2^{-5}=$ shift and add \\
\hline$h_{8}=h_{5}+h_{6}=0.1719$ & $2^{-3}+2^{-4}-2^{-6}=$ shift, add and subtract \\
\hline
\end{tabular}

\section{ECG Feature Extraction}

This section exhibits the data types of ECG signal which are adopted as input signals to the designed systems. The data represents a group of diseases in addition to the normal state.

The extracted feature from the ECG signal plays a vital role in diagnosing the cardiac disease. Therefore, it is necessary that the feature extraction system performs accurately. The purpose of feature extraction is to find as few properties as possible within ECG signal that would allow successful abnormality detection and efficient prognosis. To get the feature vector for any ECG signal, the concantination of the wavelet coefficients of the last scale level and some scaling coefficients is usually obtained [6]. In this paper, the concantination of the third or secondlevel wavelet and scaling coefficients is used to form the feature vector in each tested ECG signal. These vectors (in hexadecimals) are illustrated in Tables 6 and 7 for both standard deviation values $\sigma=1$ and $\sigma=2$,respectively. 
Table 6 Wavelet and scaling coefficients (three-level) of tested ECG signals with $\sigma=1$.

\begin{tabular}{|c|c|c|c|c|c|c|c|c|c|c|c|}
\hline \multirow{2}{*}{$\begin{array}{c}\text { Normal ECG } \\
\text { signal }\end{array}$} & Wavelet coef. & 0 & 1 & $\mathrm{FC}$ & FD & 7 & $\mathrm{FF}$ & 0 & 2 & 0 & 0 \\
\hline & Scaling coef. & 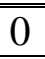 & FF & 5 & 6 & 4 & 0 & 5 & 4 & 0 & 0 \\
\hline \multirow{2}{*}{$\begin{array}{l}\text { Bradycardia } \\
\text { ECG signal }\end{array}$} & & & & $\overline{0}$ & 1 & 2 & $\overline{\mathrm{FF}}$ & 2 & $\overline{\mathrm{FC}}$ & 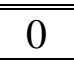 & $\overline{0}$ \\
\hline & & & 0 & FD & FD & 1 & 0 & FC & F7 & 2 & 0 \\
\hline \multirow{2}{*}{$\begin{array}{l}\text { Tachycardia } \\
\text { ECG signal }\end{array}$} & $\overline{\mathrm{Wa}}$ & & 1 & 0 & $\overline{\mathrm{FB}}$ & FC & 7 & 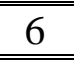 & 1 & FC & $\overline{\mathrm{FF}}$ \\
\hline & & & FF & $\overline{\mathrm{FF}}$ & 1 & 99 & $\mathrm{~F}$ & FA & F5 & $\overline{\mathrm{FD}}$ & $\mathrm{FF}$ \\
\hline \multirow{2}{*}{$\begin{array}{c}\text { Hyperkalemia } \\
\text { ECG signal }\end{array}$} & $\overline{\mathrm{Wa}}$ & & 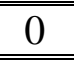 & 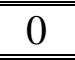 & 3 & 3 & 1 & 1 & FE & FC & 0 \\
\hline & Sca & & 0 & $\overline{\mathrm{FE}}$ & FA & FC & F9 & $\overline{E F}$ & F4 & $\overline{F D}$ & $\overline{0}$ \\
\hline \multirow{2}{*}{$\begin{array}{l}\text { WPW syndrom } \\
\text { ECG signal }\end{array}$} & $\overline{\mathrm{Wa}}$ & & FF & 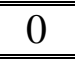 & 0 & 1 & 4 & FF & $\mathrm{FE}$ & 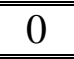 & 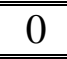 \\
\hline & $\mathrm{Sc}$ & & 2 & 4 & 5 & $\mathrm{FF}$ & 0 & FA & FA & 2 & 0 \\
\hline \multirow{2}{*}{$\begin{array}{l}\text { Pacemaker } \\
\text { ECG signal }\end{array}$} & $\overline{\mathrm{WaI}}$ & & 0 & $\mathrm{FE}$ & 1 & 0 & 1 & 3 & FF & 0 & $\overline{0}$ \\
\hline & Scal & & 0 & $\mathrm{FF}$ & 7 & 8 & 1 & $\mathrm{FF}$ & $\mathrm{FF}$ & 0 & 0 \\
\hline \multirow{2}{*}{$\begin{array}{c}\text { Established } \\
\text { angina ECG } \\
\text { signal }\end{array}$} & wav & & $\overline{0}$ & $\overline{\mathrm{FC}}$ & 2 & 2 & 1 & FD & $\mathrm{FF}$ & 3 & 1 \\
\hline & Scaling coef. & U & $\mathrm{FF}$ & 6 & $\mathrm{C}$ & 4 & 3 & FD & 3 & 5 & 1 \\
\hline
\end{tabular}

Table 7 Wavelet and scaling coefficients (two-level) of tested ECG signals with $\sigma=2$.

\begin{tabular}{|c|c|c|c|c|c|c|c|c|c|c|c|c|c|c|c|c|c|c|}
\hline \multirow{2}{*}{$\begin{array}{l}\text { Normal } \\
\text { ECG signal }\end{array}$} & $\begin{array}{l}\text { Wavelet } \\
\text { coef. }\end{array}$ & 0 & 1 & 3 & 2 & FD & FA & FC & $\mathrm{FE}$ & $\begin{array}{l}\mathrm{F} \\
\mathrm{E} \\
\end{array}$ & 0 & 3 & 3 & 3 & 2 & 1 & 0 & 0 \\
\hline & $\begin{array}{l}\text { Scaling } \\
\text { coef. }\end{array}$ & 0 & $\mathrm{FF}$ & $\mathrm{FF}$ & 1 & 3 & 0 & $\mathrm{FE}$ & 1 & 0 & \begin{tabular}{|l||}
$F$ \\
$E$
\end{tabular} & $\mathrm{FF}$ & 1 & 0 & 0 & 1 & 0 & 0 \\
\hline \multirow{2}{*}{$\begin{array}{l}\text { Bradycardi } \\
\text { a ECG } \\
\text { signal }\end{array}$} & $\begin{array}{l}\text { Wavelet } \\
\text { coef. }\end{array}$ & 0 & $\mathrm{FF}$ & FD & $\mathrm{FC}$ & FD & 1 & 4 & 4 & 4 & 4 & 2 & \begin{tabular}{l|}
$\mathrm{F}$ \\
$\mathrm{E}$
\end{tabular} & \begin{tabular}{|l|} 
F \\
A
\end{tabular} & \begin{tabular}{|l||} 
\\
$E$
\end{tabular} & 2 & 2 & 1 \\
\hline & $\begin{array}{l}\begin{array}{l}\text { Scaling } \\
\text { coef. }\end{array} \\
\end{array}$ & 0 & 1 & 1 & 0 & $\mathrm{FE}$ & FF & 0 & 1 & 1 & 0 & 1 & 3 & 0 & \begin{tabular}{l|}
$\mathrm{F}$ \\
$\mathrm{D}$
\end{tabular} & $\mathrm{FF}$ & 1 & 1 \\
\hline \multirow{2}{*}{$\begin{array}{l}\text { Tachycardi } \\
\text { a ECG } \\
\text { signal }\end{array}$} & $\begin{array}{l}\text { Wavelet } \\
\text { coef. }\end{array}$ & 1 & 1 & 2 & 3 & 2 & $\mathrm{FC}$ & F9 & $\mathrm{FD}$ & 6 & 6 & \begin{tabular}{l||}
$F$ \\
$E$
\end{tabular} & F9 & \begin{tabular}{|l|}
$\mathrm{F}$ \\
$\mathrm{B}$ \\
\end{tabular} & 3 & 5 & 2 & 0 \\
\hline & \begin{tabular}{|l}
$\begin{array}{l}\text { Scaling } \\
\text { coef. }\end{array}$ \\
\end{tabular} & 0 & 0 & 0 & 0 & 2 & 3 & 1 & $\mathrm{FB}$ & $\begin{array}{l}\mathrm{F} \\
\mathrm{C}\end{array}$ & 2 & 5 & 2 & $\begin{array}{l}\mathrm{F} \\
\mathrm{C} \\
\end{array}$ & \begin{tabular}{l|l||}
$\mathrm{F}$ \\
$\mathrm{D}$
\end{tabular} & 1 & 2 & 0 \\
\hline \multirow{2}{*}{$\begin{array}{l}\text { Hyperkalemi } \\
\text { a ECG } \\
\text { signal }\end{array}$} & \begin{tabular}{|l} 
Wavelet \\
coef.
\end{tabular} & 0 & $\mathrm{FF}$ & FD & $\mathrm{FD}$ & FD & $\mathrm{FF}$ & 1 & 6 & 7 & 3 & \begin{tabular}{l|}
$\mathrm{F}$ \\
$\mathrm{D}$ \\
\end{tabular} & $\begin{array}{l}\mathrm{F} \\
\mathrm{A}\end{array}$ & $\begin{array}{l}\mathrm{F} \\
\mathrm{D} \\
\end{array}$ & 2 & 3 & 1 & 0 \\
\hline & $\begin{array}{l}\begin{array}{l}\text { Scaling } \\
\text { coef. }\end{array} \\
\end{array}$ & 0 & 1 & 1 & $\mathrm{FF}$ & $\mathrm{FF}$ & 0 & $\mathrm{FE}$ & $\mathrm{FE}$ & 1 & 3 & 3 & 1 & $\begin{array}{l}\mathrm{F} \\
\mathrm{D}\end{array}$ & $\begin{array}{l}\mathrm{F} \\
\mathrm{E}\end{array}$ & 1 & 1 & 0 \\
\hline \multirow{2}{*}{$\begin{array}{c}\text { WPW } \\
\text { syndrom } \\
\text { ECG } \\
\text { signal }\end{array}$} & $\begin{array}{l}\text { Wavelet } \\
\text { coef. }\end{array}$ & 0 & 1 & 1 & 1 & 2 & 1 & FE & FB & 0 & 4 & 3 & \begin{tabular}{|l|}
$\mathrm{F}$ \\
$\mathrm{E}$
\end{tabular} & $\begin{array}{l}\mathrm{F} \\
\mathrm{B}\end{array}$ & $\mathrm{FF}$ & 3 & 2 & 1 \\
\hline & $\begin{array}{l}\begin{array}{l}\text { Scaling } \\
\text { coef. }\end{array} \\
\end{array}$ & 0 & 0 & 0 & 0 & $\mathrm{FF}$ & 0 & 3 & 0 & $\begin{array}{l}\mathrm{F} \\
\mathrm{D}\end{array}$ & \begin{tabular}{|l|}
$F$ \\
$E$
\end{tabular} & 1 & 4 & 0 & \begin{tabular}{l|}
$\mathrm{F}$ \\
$\mathrm{D}$ \\
\end{tabular} & $\mathrm{FF}$ & 1 & 1 \\
\hline \multirow{2}{*}{$\begin{array}{c}\text { Pacemaker } \\
\text { ECG } \\
\text { signal }\end{array}$} & $\begin{array}{l}\text { Wavelet } \\
\text { coef. }\end{array}$ & 0 & $\mathrm{FE}$ & $\mathrm{FC}$ & $\mathrm{FC}$ & $\mathrm{FF}$ & 4 & 7 & 5 & $\mathrm{FF}$ & \begin{tabular}{|l|}
$\mathrm{F}$ \\
$\mathrm{C}$
\end{tabular} & $\mathrm{FF}$ & 1 & 2 & 1 & 0 & 0 & 0 \\
\hline & $\begin{array}{l}\begin{array}{l}\text { Scaling } \\
\text { coef. }\end{array} \\
\end{array}$ & 0 & 1 & 1 & 0 & $\mathrm{FE}$ & FD & $\mathrm{FF}$ & 3 & 3 & 0 & \begin{tabular}{l|}
$\mathrm{F}$ \\
$\mathrm{E}$ \\
\end{tabular} & $\mathrm{FF}$ & 0 & 1 & 0 & 0 & 0 \\
\hline \multirow{2}{*}{$\begin{array}{c}\text { Establishe } \\
\text { d angina } \\
\text { ECG } \\
\text { signal }\end{array}$} & $\begin{array}{l}\text { Wavelet } \\
\text { coef. }\end{array}$ & $\begin{array}{l}\mathrm{F} \\
\mathrm{F}\end{array}$ & $\begin{array}{l}\mathrm{F} \\
\mathrm{D} \\
\end{array}$ & $\mathrm{FF}$ & 4 & 6 & 1 & 0 & 4 & 3 & $\mathrm{FF}$ & \begin{tabular}{l|}
$\mathrm{F}$ \\
$\mathrm{C}$
\end{tabular} & $\begin{array}{l}\mathrm{F} \\
\mathrm{C}\end{array}$ & $\begin{array}{l}\mathrm{F} \\
\mathrm{D} \\
\end{array}$ & $\begin{array}{l}\mathrm{F} \\
\mathrm{E}\end{array}$ & 0 & 1 & 1 \\
\hline & $\begin{array}{l}\text { Scaling } \\
\text { coef. }\end{array}$ & 1 & 1 & $\mathrm{FE}$ & FD & 2 & 3 & FF & FF & 2 & 2 & 0 & $\mathrm{FF}$ & 0 & $\mathrm{FF}$ & $\mathrm{FF}$ & 0 & 1 \\
\hline
\end{tabular}




\section{Conclusions}

ECG-based FIR wavelet filter banks have been designed. The Gaussian function has been utilized as a mother wavelet function stage withan advancing difference stage. Sampled versions of such wavelet function are used as impulse responses to the designed wavelet filter banks. These banks have been realized in a highly-efficient lattice structures which are easy to implement. The numbers of filter banks coefficients have been reduced to more than half of their original values. Resulting in reducing the number of multiplications and improving the filter banks efficiencies as the final number of computationsperformed is reduced. This may lead to less-complex hardware implementations. SOPOT method has been applied to quantized different multiplier values, leading to multiplierless realizations for such multiplier values (shift and add only).

In spite of the need for at least more than one level wavelet decompositions for ECGQRS feature extraction, the proposed lattice structures can also serve for that purpose because of their less-complex and computational-efficient realizations.

\section{References}

[1]Z. German-Sallo, "Applications of Wavelet Analysis in ECG Signal Processing”, Ph. D. Thesis,Technical University Of Cluj-Napoca, 2005.

[2] M. Bani-Hasan, Y. Kadah, and F. El-Hefnawi, "Identification of Cardiac Arrhythmias using Natural Resonance Complex Frequencies ", International Journal of Biological and Life Sciences 6:3, BiomedicalDepartment, Faculty of Engineering, Cairo University, Egypt,2010.

[3] M. Engin, "ECG Beat Classification Using Neuro-Fuzzy Network”, Electrical and Electronics Engineering Department, Faculty of Engineering, Ege University, Bornova, Izmir 35100, Turke, 27 April 2004.

:http://csc.lsu.edu/ jianhua/archana.pdf

[4] R. Wahidabanu and P. Sasikala, "Robust R Peak and QRS detection in Electrocardiogram using Wavelet Transform",Govt. College of Engineering ,Salem, Tamilnadu, India, International Journal of Advanced Computer Science and Applications, Vol. 1, No.6, December 2010.

[5] S. Mahmoodabadi,A. Ahmadian and M. Abolhasani, "ECG Feature ExtractionUsing Daubechies Wavelets", Tehran University of Medical Sciences (TUMS),Tehran, Iran, September 7-9, 2005.

:http://rcstim.tums.ac.ir/db/papers/45.pdf

[6]S. Karpagachelvi,M. Arthanari and M. Sivakumar, "ECG Feature Extraction TechniquesA Survey Approach",International Journal of Computer Science and Information Security,Vol.8,No.1,April,2010.

[7] A. Basuhail and Y. Al-Otaibi, "Processing Of Arabic Speech Using Multi-Level Wavelet Transform", Jeddah College of Technology, Jeddah, KSA http://ipac.kacst.edu.sa/eDoc/2005/145830_1.pdf

[8] M. Alfaouri and K. Daqrouq, "ECG Signal Denoising By Wavelet Transform Thresholding",American Journal of Applied Sciences Vol.3,No. 3, pp. 276-281, 2008.

[9] S. Haddad, R.Houben and W. Serdijn, "First Derivative Gaussian Wavelet Function Employing Dynamic Translinear Circuits for Cardiac Signal Characterization",Electronics Research Laboratory, Faculty of Information Technology and Systems, Delft University of Technology.

:http://citeseerx.ist.psu.edu/viewdoc/download?doi=10.1.1.9.9856 \&rep=rep1\&type=pdf

[10]D.Sripathi, "Efficient Implementations of Discrete Wavelet Transforms Using FPGAs", Master's Thesis, Electrical and Computer Engineering Department, Florida State University, November 2003.

http://etd.lib.fsu.edu/theses/available/etd-11242003-185039/unrestricted/ 10 ds chapter3.pdf

[11]D. Hale, "Recursive Gaussian Filters", Center for Wave Phenomena , Colorado School of Mines, Golden CO 80401, USA.

http://www.cwp.mines.edu/Meetings/Project06/cwp546.pdf.

$$
\text { The work was carried out at the college of Engineering. University of Mosul }
$$

